\title{
Delirium Assessment in Critically III Older Adults
}

\section{Considerations During the COVID-19 Pandemic}

\author{
Maria C. Duggan, MD, MPH ${ }^{a, b, *}$, Julie $\operatorname{Van}^{c, d}$, \\ Eugene Wesley Ely, MD, MPH ${ }^{\mathrm{b}, \mathrm{c}, \mathrm{d}}$
}

\section{KEYWORDS}

- Delirium • Screening • Assessment • Critical care • Intensive care unit

- Older adults • Geriatrics • Pandemic

\section{KEY POINTS}

- Delirium is common in critically ill older adults, who are more vulnerable to adverse outcomes, as was on full display in the Coronavirus disease 2019 (COVID-19) pandemic.

- Regular assessment for delirium is recommended, and many validated tools exist for detecting delirium in critically ill older adults. This assessment was a challenge amid the COVID-19 pandemic, when personnel and personal protective equipment were limited.

- Special considerations are necessary for patients with certain conditions (eg, sensory impairment, chronic neurodegenerative conditions, acute neurologic injury), which both increase risk for delirium and may be mistaken for delirium. In COVID-19, these patients proved especially vulnerable to delirium and may have greater long-term cognitive impairment as a result. Ongoing studies are pursuing this aspect of survivorship from the pandemic.

\section{INTRODUCTION}

If an experiment were designed to make delirium as big a problem as possible in an intensive care unit (ICU), Coronavirus disease 2019 (COVID-19) would be it. Delirium (an acute disturbance of consciousness with inattention accompanied by a change in cognition or perceptual disturbance that fluctuates over time) was already prevalent in the ICU before the pandemic of the novel severe acute respiratory syndrome

\footnotetext{
a Division of Geriatric Medicine, Vanderbilt University School of Medicine, Nashville, TN, USA;

b Department of Veteran Affairs, Geriatric Research Education and Clinical Center (GRECC), Tennessee Valley Healthcare System, 1310 24th Avenue South, Nashville, TN 37212, USA; ' Division of Allergy, Pulmonary, and Critical Care Medicine, Vanderbilt University School of Medicine, Nashville, TN, USA; ${ }^{d}$ Center for Health Services Research (HSR), Vanderbilt University Medical Center, 2525 West End Avenue, Suite 450, Nashville, TN 37203, USA

* Corresponding author. 2525 West End Avenue, Suite 450, Nashville, TN 37203.

E-mail address: Mariu.duggan@vumc.org
} 
Coronavirus 2 (SARS-CoV-2) causing COVID-19. Before the pandemic, delirium affected up to $80 \%$ of critically ill adults, with each year more than 65 years of age increasing the odds of delirium by $2 \%$. Older adults were already more prone to experiencing delirium because of multiple predisposing risk factors: dementia (odds ratio [OR], 2.3-4.7), hearing impairment (OR, 3.0), vision impairment (OR, 2.1-3.5), functional impairment (OR, 4.0), age greater than or equal to 75 years (OR, 4.0), and polypharmacy. ${ }^{1,2}$ On top of all these risk factors, the COVID-19 pandemic has made that delirium risk even higher for older adults through isolation, immobilization, and removing family from the bedside.

The pandemic has raised many challenges in managing critically ill older adults, a population preferentially killed by COVID-19. Mortalities for hospitalized adults aged in their $60 \mathrm{~s}, 70 \mathrm{~s}$, and 80 s are $18.7 \%, 35.8 \%$, and $60.6 \%$, respectively. ${ }^{3}$ Coupled with delirium, which independently increases risk for prolonged mechanical ventilation, longer ICU and hospital stay, institutionalization, functional dependence, longterm cognitive impairment, and higher mortality up to 2 years after discharge, ${ }^{4-11}$ COVID-19 poses a huge challenge for older adults.

Even for survivors who physically recover from critical illness, delirium can have long-standing neuropsychiatric effects. It may also lead to psychiatric illnesses, including depression and posttraumatic stress disorder, and these effects are likely to be worse during the pandemic because of the restriction of family presence. Delirium itself may last for weeks to months, and for some patients it may both unmask and lead to the development of dementia with substantial declines in memory and executive functioning. ${ }^{6}$ Delirium increases the odds for developing dementia by 12.5 times. $^{12}$ In the Bringing to Light the Risk Factors and Incidence of Neuropsychological Dysfunction in ICU Survivors (BRAIN-ICU) study, a longer duration of delirium was associated with worse long-term global cognition and executive function, independent of sedative or analgesic medication use, age, preexisting cognitive impairment, coexisting disease, and severity of illness in the ICU. ${ }^{6}$ This finding is particularly important for older adults, who place a high value on their cognitive status and fear developing dementia. ${ }^{13}$

To spare this vulnerable population of older adults from these poor outcomes associated with delirium, early recognition of delirium is critical in order to best lessen the burden of delirium. This article discusses practical recommendations for delirium screening in the COVID-19 pandemic era, tips for training health care workers in delirium screening, validated tools for detecting delirium in critically ill older adults, and approaches to special populations of older adults (eg, sensory impairment, dementia, acute neurologic injury).

\section{WHY SHOULD DELIRIUM SCREENING BE A PRIORITY DURING THE COVID-19 PANDEMIC?}

The COVID-19 pandemic may increase delirium risk because of viral factors (direct central nervous system invasion, induction of central nervous system inflammatory mediators), prolonged mechanical ventilation and the deep sedation that accompanies it, immobilization, other organ failures, and environmental factors such as isolation and absence of family.

Even before the COVID-19 pandemic, up to $75 \%$ of cases of delirium were missed without formal delirium screening. ${ }^{14}$ Delirium has been reported in up to two-thirds of patients with acute respiratory distress syndrome caused by COVID-19. ${ }^{15}$ The number of undetected delirium cases is likely even higher now because of the challenges highlighted in Table 1. 


\begin{tabular}{|c|c|}
\hline Challenges & Potential Solutions \\
\hline $\begin{array}{l}\text { HCWs limit contact with patients to conserve } \\
\text { PPE and reduce risk of COVID-19 } \\
\text { transmission }\end{array}$ & $\begin{array}{l}\text { - Equip other HCWs beyond nurses to screen } \\
\text { for delirium through traininga } \\
\text { - Use brief delirium screening tools; eg, 2- } \\
\text { min CAM-ICU }\end{array}$ \\
\hline $\begin{array}{l}\text { Shortages of personnel caused by surge } \\
\text { volumes }\end{array}$ & $\begin{array}{l}\text { - Train other disciplines of HCWs in brief } \\
\text { delirium screening as above }\end{array}$ \\
\hline $\begin{array}{l}\text { Assessing a change from baseline mental } \\
\text { status (feature } 1 \text { of } C A M-I C U \text { ) is } \\
\text { challenging with family visitation } \\
\text { restricted }\end{array}$ & $\begin{array}{l}\text { - Involve family remotely through use of } \\
\text { smartphones or tablets during or after } \\
\text { rounds to facilitate communication with } \\
\text { patient } \\
\text { - Call nursing homes for patients admitted } \\
\text { from a nursing home to understand } \\
\text { baseline mental status }\end{array}$ \\
\hline $\begin{array}{l}\text { Surgical masks on HCWs impede older adults' } \\
\text { comprehension of delirium screening } \\
\text { questions, especially in hearing } \\
\text { impairment }\end{array}$ & $\begin{array}{l}\text { - Reduce background noise } \\
\text { - Speak slowly, clearly, in low pitch } \\
\text { - Use sound amplifiers (pocket talkers) } \\
\text { - Have hearing aid batteries available } \\
\text { - Ask family to bring hearing aids } \\
\text { - Use transparent surgical masks if available } \\
\text { (https://www.theclearmask.com) }\end{array}$ \\
\hline $\begin{array}{l}\text { PPE may make certain patients with } \\
\text { dementia more paranoid and not willing } \\
\text { to participate in delirium screening }\end{array}$ & $\begin{array}{l}\text { - Use large signs on gowns with pictures of } \\
\text { providers and names/roles written in large } \\
\text { font } \\
\text { - Hand out baseball cards to patients for } \\
\text { providers with picture, name, role } \\
\text { - Allow family to visit patients with } \\
\text { cognitive impairment } \\
\text { - Be aware that refusal to participate in } \\
\text { CAM-ICU may be a sign of delirium } \\
\end{array}$ \\
\hline $\begin{array}{l}\text { Patients with dementia or history of stroke } \\
\text { commonly have aphasia. Families are } \\
\text { helpful in facilitating communication, but } \\
\text { are not present at bedside }\end{array}$ & $\begin{array}{l}\text { - Speak slowly } \\
\text { - Ask yes/no questions } \\
\text { - Involve family remotely through use of } \\
\text { smartphones or tablets at the bedside to } \\
\text { facilitate communication with patient } \\
\text { - Allow family to visit patients with } \\
\text { cognitive impairment }^{\text {b }}\end{array}$ \\
\hline $\begin{array}{l}\text { Delirium is unable to be assessed during deep } \\
\text { sedation administered during } \\
\text { neuromuscular blockade and proning to } \\
\text { treat respiratory failure }\end{array}$ & $\begin{array}{l}\text { - Assess sedation daily and limit as much as is } \\
\text { feasible, adhering to A2F bundle }\end{array}$ \\
\hline
\end{tabular}

The A2F bundle stands for assess, prevent, and manage pain; both spontaneous awakening trial and spontaneous breathing trial; choice of sedation and analgesia; delirium assessment, prevention, and management; early mobility and exercise; and family engagement.

Abbreviations: CAM-ICU, Confusion Assessment Method for the ICU; HCW, health care worker; PPE, personal protective equipment.

a The CAM-ICU can be taught to ICU staff in less than 30 minutes and administered to patients in less than 2 minutes.

${ }^{b}$ Allow family visitation provided that the family member passes a health screen and wears a mask. 
Delirium can be recognized early with formal screening, prompting an expedited clinical assessment that may identify problems sooner and lead to earlier treatment and resolution. In addition, early recognition of delirium can help optimize nonpharmacologic measures, which have been proven to reduce delirium days and potentially help reduce the suffering of patients and families that accompanies delirium. ${ }^{16}$

Many expert guidelines and professional societies and organizations have strongly recommended delirium monitoring twice daily: The ICU Pain, Agitation, and Delirium Clinical Practice Guidelines by the Society of Critical Care Medicine (grade 1B) ${ }^{17}$ and the updated Pain, Agitation, Delirium, Immobility, and Sleep (PADIS) guidelines, ${ }^{18}$ hospital standards for surgical care of older adults by the Coalition for Quality in Geriatric Surgery, ${ }^{19}$ and the Age-Friendly Health Systems Initiative of the Institution for Healthcare Improvement.

Studies examining the impact of delirium screening interventions in critically ill patients have shown improvements in clinical outcomes. One of the most well-known strategies for preventing delirium in critically ill patients is the ABCDEF (A2F) bundle (assess, prevent, and manage pain; both spontaneous awakening trial and spontaneous breathing trial; choice of sedation and analgesia; delirium assessment, prevention, and management; early mobility and exercise; and family engagement). The A2F bundle was associated with lower likelihood of hospital death within 7 days, next-day mechanical ventilation, coma, delirium, physical restraint use, immobility, ICU readmission, and discharge to a facility. ${ }^{20-25}$ Greater adherence to the bundle was associated with greater improvements in each of these outcomes. Although this bundle was implemented in patients of all ages, it is arguably most important to implement for older adults, who are predisposed to newly acquired deficits and diseases when they experience critical illness.

However, there is insufficient high-quality evidence to show that delirium screening alone is beneficial. Teasing out the effect of delirium screening is challenging because many studies, such as those involving the A2F bundle, examine the impact of delirium screening as part of a bundle of management strategies.

\section{WHO SHOULD SCREEN FOR DELIRIUM IN THE INTENSIVE CARE UNIT?}

During a pandemic where personnel may be limited, other health care workers should be trained in administering validated delirium screening tools at least once per shift and with every change in mental status. Even with adequate nursing staff, ensuring the assessment of a patient's brain health is not solely the bedside nurses' responsibility but is a shared responsibility of the interdisciplinary team. All clinicians have a role in this and should be able to screen a patient for delirium if they are caring for a patient and are the first to recognize its symptoms. Members of the interdisciplinary team should be aware of the common clinical presentation of delirium and possible contributing factors. For instance, a pharmacist performing a medication reconciliation with a patient who is unable to stay attentive should be trained to recognize this as a potential sign of delirium and to relay this information to the clinician with pertinent recommendations for possible contributing medications.

Family members and caregivers should be seen as an extension of the health care team and may be instrumental in recognizing subtle changes from a patient's baseline mental status. In addition to helping recognize delirium, family members are often most effective at reorienting patients, knowing ways to calm them down, helping with feeding and hydration, and bringing in hearing aids and glasses. This point is particularly true for individuals with dementia. Engaging caregivers as active members of the health care team improves patient care, education, and communication, but it 
can also facilitate the transition from hospital to home and prepare caregivers for delirium prevention and recognition after discharge. Education materials on delirium for families are available at ICUdelirium.org. ${ }^{26}$ Although family visitation may be restricted during the COVID-19 pandemic, it is possible to involve family remotely through use of smartphones or tablets during or after rounds.

\section{HOW TO SCREEN FOR DELIRIUM IN THE INTENSIVE CARE UNIT?}

The PADIS guidelines recommend delirium screening using the Confusion Assessment Method-ICU (CAM-ICU) ${ }^{27}$ or the Intensive Care Delirium Screening Checklist (ICDSC). ${ }^{28}$ The CAM-ICU and the ICDSC were developed to detect delirium in nonverbal patients, primarily in the ICU. Although many tools exist to detect delirium, the CAM-ICU and the ICDSC are the most valid and reliable tools for delirium screening among adult ICU patients. ${ }^{17,29,30}$ Both tools have been translated and validated in several other languages. They are reviewed here.

\section{The Confusion Assessment Method-Intensive Care Unit}

The CAM-ICU was adapted from the Confusion Assessment Method ${ }^{31}$ and uses the same feature structure: (1) acute onset or fluctuations in mental status from baseline, (2) inattention, (3) disorganized thinking, and (4) an altered level of consciousness (Fig. 1). The CAM-ICU was validated by the Diagnostic and Statistical Manual of Mental Disorders, fourth edition (DSM-IV) criteria as gold standard, with sensitivity of $80 \%$ and specificity of $96 \%$. $^{27,30}$

The CAM-ICU is positive (ie, delirium present) if features 1 and 2 and either feature 3 or 4 are present. Patients who are not in a stupor or coma are assessed for these features using objective criteria and direct patient assessment. The assessment involves the following:

- Comparing the patient's current mental status with the patient's baseline (feature 1)

- Evaluating attention by asking the patient to squeeze on the letter $\mathrm{A}$ while reading a string of 10 letters (feature 2)

- Evaluating level of consciousness with the use of a sedation scale (eg, Richmond Agitation Sedation Scale $[\mathrm{RASS}]^{32,33}$ or Sedation-Agitation Scale [SAS] ${ }^{34}$ ) (feature 3)

- A set of 4 yes/no questions followed by a 2-stage command (feature 4)

The CAM-ICU can be taught to ICU staff in less than 30 minutes and administered to patients in less than 2 minutes. ${ }^{35}$ Ten clinical pearls related to administering the CAMICU are listed in Box 1.

\section{Intensive Care Delirium Screening Checklist}

The ICDSC is a checklist with 8 questions that allows ICU staff to observe the following delirium symptoms over a period of 8 to 12 hours: altered level of consciousness, inattention, delusion or hallucination, disorientation, inappropriate mood or speech, psychomotor agitation, sleep/wake cycle disturbance, and symptom fluctuation. ${ }^{28}$ Patients do not have to be verbal in order to undergo the ICDSC. Scores range from 0 to 8 and are associated with a classification (0, normal; $1-3$, subsyndromal delirium; 4-8, delirium). The ICDSC is a valid and reliable tool with sensitivity and specificity studies of $74 \%$ and $82 \%$, respectively. ${ }^{30}$ 
A

RICHMOND AGITATION-SEDATION SCALE (RASS)

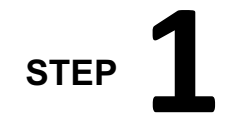

\section{Level of Consciousness Assessment}

\section{Scale Label Description}

\begin{tabular}{|c|c|c|}
\hline+4 & COMBATIVE & Combative, violent, immediate danger to staff \\
\hline+3 & VERY AGITATED & Pulls to remove tubes or catheters; aggressive \\
\hline+2 & AGITATED & Frequent nonpurposeful movement, fights ventilator \\
\hline+1 & RESTLESS & Anxious, apprehensive, movements not aggressive \\
\hline 0 & ALERT \& CALM & Spontaneously pays attention to caregiver \\
\hline-1 & DROWSY & $\begin{array}{l}\text { Not fully alert, but has sustained awakening to voice } \\
\text { (eye opening \& contact }>10 \text { s) }\end{array}$ \\
\hline-2 & LIGHT SEDATION & Briefly awakens to voice (eyes open $\&$ contact $<10$ s) \\
\hline \multirow[t]{2}{*}{-3} & MODERATE SEDATION & Movement or eye opening to voice (no eye contact) \\
\hline & If RASS is $\geq-3$ proc & eed to CAM-ICU (Is patient CAM-ICU positive or negative?) \\
\hline-4 & DEEP SEDATION & $\begin{array}{l}\text { No response to voice, but movement or eye opening } \\
\text { to physical stimulation }\end{array}$ \\
\hline-5 & UNAROUSABLE & No response to voice or physical stimulation \\
\hline
\end{tabular}

B STEP

\section{Content of Consciousness Assessment}

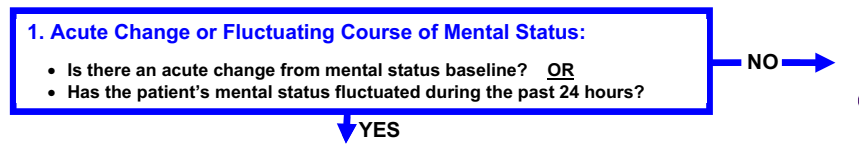

CAM-ICU negative NO DELIRIUM

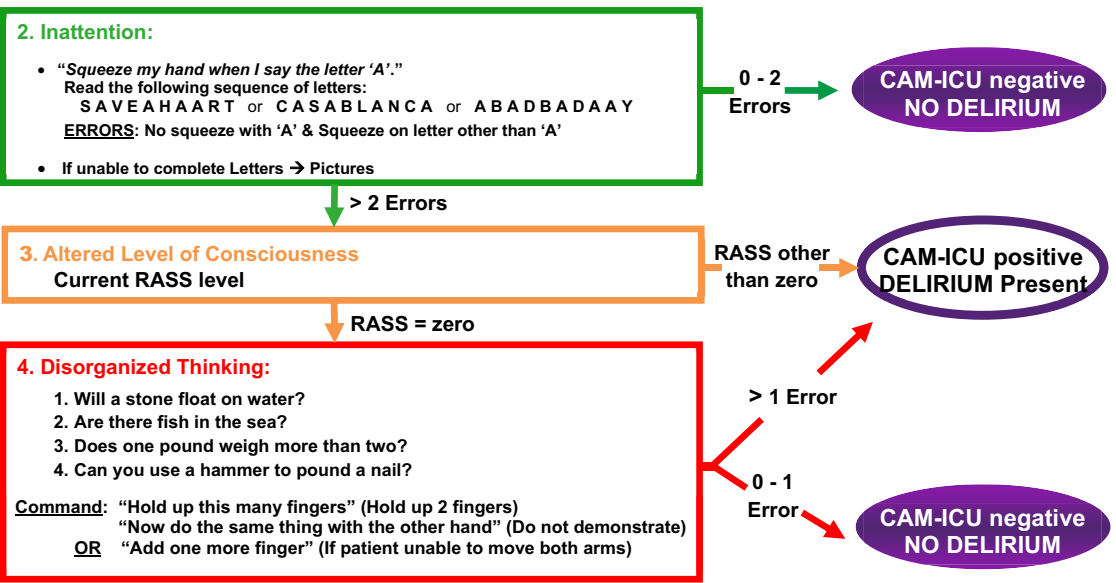


Box 1

Ten clinical pearls related to delirium assessment

1. Assessment is fast: $90 \%$ of RASS/CAM-ICU assessments take less than 1 minute. The other $10 \%$ take only a few minutes. Speed and ease of use make this feasible on a large scale multiple times daily.

2. RASS and CAM-ICU: implementing RASS without CAM-ICU (sedation scale without delirium tool) leaves only half of consciousness assessed (arousal, not content), is clinically unsatisfying, and hurts compliance.

3. Tailor examination: you do not have to do every CAM-ICU feature if you get your answers via a brief examination sooner.

4. Starting with features 1 and 3: feature 1 is comparing patients with their baseline mental status, and feature 3 is about their level of consciousness now. Because many ICUs repeat sedation scale assessment every 2 to 4 hours, these data are readily available. A quick mantra: "Is patient at the baseline or fluctuating + RASS now."

5. Inattention (feature 2): this is the cardinal feature and must be present to diagnose delirium. Feature 2 is quick and simple. Ninety percent of evaluations are done using only hand squeezes on correct letters or numbers. The picture method of screening is needed for inattention in less than $5 \%$.

6. Hand squeezing: in the absence of other specific neurologic diagnoses, a patient who squeezes on all letters, squeezes on no letters, or misses more than 2 letters/numbers/ pictures is inattentive and feature 2 positive. With a RASS other than 0 , the patient is delirious.

7. Unable to assess: this term is only recorded when patients are in stupor/coma (RASS $-4 /-5$ ).

8. Rare feature 4 : it is only necessary to proceed to Feature 4 (disorganized thinking) when a patient is feature 2 positive (inattentive) and awake and alert (RASS 0 ) at the time of CAMICU evaluation.

9. Subsyndromal delirium: patients may have some features without the full syndrome of delirium (eg, feature 2 only or feature 1 and feature 4 only). This condition is a (subsyndromal) intermediate state between normal and delirium. Reassess with CAM-ICU frequently to determine the clinical course of the emerging brain dysfunction.

10. Key to success: physicians and nurses must work together. The team must understand the definition of delirium and its prognostic implications, modifiable causes, and treatment options. Enthusiasm is destroyed when physicians do not respond to nurses who report that a patient is CAM-ICU positive. Overcome this implementation barrier by engaging and educating all members of the ICU team and having experts.

Adapted from Top 10 Teaching Tips for Delirium Monitoring. Available at: https://uploads-ssl. webflow.com/5b0849daec50243a0a1e5e0c/5bad3d17cc14608db92dbeed_Top-10-Tips-for-

Teaching-Delirium-Monitoring.pdf; with permission.

\section{SCREENING OUTSIDE THE INTENSIVE CARE UNIT}

Because delirium may initially present in nursing homes or emergency departments (EDs) and persists beyond the ICU, all health care settings that encounter acutely ill

Fig. 1. (A) The Richmond Agitation-Sedation Scale (RASS). (B) The Confusion Assessment Method for the ICU (CAM-ICU). The RASS is a valid and reliable tool to monitor level of consciousness, which is feature 3 of the CAM-ICU. The CAM-ICU is a valid and reliable tool to screen for delirium. (Copyright @ 2002 , E. Wesley Ely, MD, MPH, and Vanderbilt University. All rights reserved.) 
adults should use appropriate delirium screening tools. Some of these tools are reviewed later. More information on optimizing delirium screening in settings outside the ICU can be found on the Age-Friendly Health Systems initiative's Web site. ${ }^{36}$

\section{Delirium Triage Screen}

The Delirium Triage Screen (DTS) is an ultrabrief delirium screen developed for use in a busy clinical setting, such as the ED. This approach uses a very brief ( $<20$ seconds) delirium screen to rapidly rule out delirium if negative, and triggering a confirmatory assessment if positive. In older ED patients, the DTS is $98 \%$ sensitive and $55 \%$ specific for delirium. ${ }^{37}$

The DTS has only 2 components: (1) altered level of consciousness assessed by using an arousal tool; and (2) inattention, which is assessed by asking the patient to spell "lunch" backward. The DTS is considered negative if the patient has a normal level of consciousness and makes zero or 1 error when spelling "lunch" backward. If the patient has an altered level of consciousness or makes 2 or more errors during the spelling test, the examination is considered positive and a more specific test (Brief Confusion Assessment Method [bCAM] or CAM-ICU) is required to confirm a diagnosis of delirium.

The geriatric ED guidelines recommend the DTS as the first step in delirium screening. ${ }^{38}$

\section{The Brief Confusion Assessment Method}

The bCAM was adapted from CAM-ICU for use in verbal patients in the ED. ${ }^{37}$ The geriatric ED guidelines recommend the bCAM as the next step in delirium screening for a positive DTS. ${ }^{38}$ The bCAM was also validated in a geriatric ward setting. ${ }^{37}$ The bCAM had a sensitivity of $70 \%$ to $84 \%$ and a specificity of $96 \%$ to $97 \% .^{37}$

The bCAM uses the same 4 features as the CAM-ICU. Feature 2 (inattention) is assessed by asking the patient to recite the months backward from December to July. Administration of the bCAM is otherwise identical to the CAM-ICU. Scoring varies slightly. Feature 2 is positive if 2 or more errors are made, and feature 4 is positive if any errors are made.

\section{IDENTIFYING DELIRIUM SUPERIMPOSED ON DEMENTIA}

Delirium that occurs in patients with dementia is referred to as delirium superimposed on dementia (DSD). Older adults with dementia have reduced cognitive reserve, making them more likely to develop delirium with fewer precipitating factors. ${ }^{1}$ DSD is associated with adverse outcomes: accelerated cognitive and functional decline, institutionalization, and mortality. ${ }^{12,39,40}$ Diagnosing DSD can be difficult for many reasons.

First, although dementia is common, affecting up to a quarter of hospitalized older adults, it often goes unrecognized. ${ }^{41}$ Dementia may be particularly difficult to recognize in critically ill older adults who are noncommunicative because of critical illness or the treatments that accompany it. The AD8 is an 8-item proxy screening tool for dementia that has been validated in hospitalized adults with delirium ${ }^{42}$ and in the ICU. ${ }^{43}$ The AD8 can be administered to a family member over the phone. Recognizing dementia is important to help identify those at highest risk of delirium and ensure optimal nonpharmacologic prevention.

Second, $80 \%$ of patients with dementia experience behavioral and psychiatric symptoms at some point in the disease course. Although manifestations of 
dementia, these symptoms may resemble features of delirium. ${ }^{44}$ These symptoms may include sleep disturbances, paranoia, and anxiety in earlier stages, and may progress to accusatory behavior, irritability, wandering, agitation, hallucinations, and aggression in later stages. ${ }^{45}$ Understanding a patient's baseline behavioral and psychiatric state is key to teasing out whether a clinical presentation is likely to be caused by delirium.

In addition, certain types of dementia can have acute changes in cognition in the natural course of the disease that may be mistaken for delirium. For example, dementia with Lewy bodies, the third most common type of dementia, can have fluctuating levels of consciousness with inattention and psychosis. ${ }^{46}$ Vascular dementia can have acute worsening of cognition caused by vascular events, and it can be difficult to ascertain whether a change is the next stepwise decline or delirium of another cause. It is safest to assume acute changes in cognition are delirium and to rule out other contributing factors before attributing changes to progression of dementia.

In addition, delirium screening tests require the participant to perform tasks that depend on multiple cognitive domains: visual and auditory processing, visual processing, language, and motor execution. Dementia does not only affect memory but can also affect other cognitive domains, making delirium screening difficult to interpret. Although mild attention deficits are common, starting in the early stages of dementia, visual attention is often preserved even in advanced stages of dementia. ${ }^{47}$

\section{Assessing Baseline Mental Status}

For patients with dementia, establishing the patient's baseline mental state is imperative to determining the acuity of mental status change and fluctuations that are associated with delirium. Providers should ask a proxy that is most familiar with the patient, whether a family member, personal caregivers, or nursing home provider. This requirement can be challenging with visitation restrictions if family contact information is unknown. If possible, the patient's baseline level of consciousness and ability to speak and follow commands should be elicited. In addition, any behavioral or psychiatric symptoms of dementia and triggers should be identified, as well as actions that help redirect the patient. If baseline cognition is unable to be confirmed, it should never be assumed that the patient is at baseline.

\section{Tools Validated to Detect Delirium Superimposed on Dementia}

Few studies report diagnostic validity of delirium screening tools for detecting DSD (Table 2). Based on available evidence, the CAM-ICU has the most support for use in the diagnosis of DSD in critically ill older adults. ${ }^{48}$ The CAM-ICU has an option to use a visual attention form to assess feature 2, the core feature of delirium, which can be useful in identifying delirium in patients with dementia. Other screening tools validated in larger populations of patients with dementia (the 4As test, ${ }^{49} 6$-Item Cognitive Impairment Test, ${ }^{50} 3$-Item Screener ${ }^{51}$ ) require patients to be verbal, which is often a barrier to implementation in the ICU.

\section{OTHER SPECIAL CONSIDERATIONS Sensory Impairment}

Hearing impairment can result in inappropriate answers to questions if an older adult does not correctly interpret the information communicated by the health care provider. This situation can lead to a false-positive delirium screen, which may trigger unnecessary, burdensome testing. For delirium screens to be accurate and reliable, it is 


\begin{tabular}{|c|c|c|c|c|c|}
\hline $\begin{array}{l}\text { Screening Tool } \\
\text { (Author, Year) }\end{array}$ & Setting & $\begin{array}{l}\text { Total } \\
\text { Sample } \\
\text { (N) }\end{array}$ & $\begin{array}{l}\text { Sample } \\
\text { with } \\
\text { Dementia, } \\
\text { N (\%) }\end{array}$ & $\begin{array}{l}\text { Sensitivity } \\
(\%)\end{array}$ & $\begin{array}{l}\text { Specificity } \\
(\%)\end{array}$ \\
\hline $\begin{array}{l}\text { Short Portable } \\
\text { Mental Status } \\
\text { Questionnaire } \\
\text { (Erkinjuntti } \\
\text { et al, }{ }^{63} 1987 \text { ) }\end{array}$ & Geriatric ward & 282 & $34(12)$ & $7.3-98$ & $82-100$ \\
\hline $\begin{array}{l}\text { Confusion } \\
\text { Assessment } \\
\text { Method } \\
\text { (Inouye et al, } \\
\text { 1990) }\end{array}$ & $\begin{array}{l}\text { Internal medicine } \\
\text { ward }\end{array}$ & 56 & $12(21)$ & $94-100$ & $90-05$ \\
\hline $\begin{array}{l}\text { Confusion } \\
\text { Assessment } \\
\text { Method } \\
\text { (Hestermann } \\
\text { et al, }{ }^{64} \text { 2009) } \\
\end{array}$ & Geriatric ward & 39 & $33(85)$ & 77 & $96-100$ \\
\hline $\begin{array}{c}\text { Delirium Rating } \\
\text { Scale (Rosen } \\
\text { et al, }{ }^{65} \text { 1994) }\end{array}$ & Geriatric ward & 791 & $197(27)$ & 94 & 82 \\
\hline $\begin{array}{l}\text { Cognitive Test } \\
\text { for Delirium } \\
\text { (Hart et al, }{ }^{66} \\
1996 \text { ) } \\
\end{array}$ & ICU & 103 & $26(25)$ & 100 & 95 \\
\hline $\begin{array}{l}\text { CAM-ICU (Ely } \\
\text { et al, }{ }^{67} \text { 2001) } \\
\end{array}$ & ICU & 96 & $12(15)$ & $93-100$ & $98-100$ \\
\hline $\begin{array}{l}\text { CAM-ICU (Ely } \\
\text { et al, }{ }^{35} \text { 2001) } \\
\end{array}$ & ICU & 38 & $11(29)$ & $95-100$ & 89-93 \\
\hline $\begin{array}{l}\text { CAM-ICU } \\
\text { (Mitasova } \\
\text { et al, }{ }^{54} \text { 2011) } \\
\end{array}$ & Stroke unit & 129 & $41(32)$ & 76 & 98 \\
\hline $\begin{array}{l}\text { EEG (Thomas } \\
\text { et al, }{ }^{68} 2007 \text { ) }\end{array}$ & Geriatric ward & 35 & $35(100)$ & 67 & 91 \\
\hline $\begin{array}{l}4 \text { As Test (Bellelli } \\
\text { et } \text { al }^{49} \text { 2014) }\end{array}$ & $\begin{array}{l}\text { Geriatric ward or } \\
\text { inpatient } \\
\text { rehabilitation }\end{array}$ & 234 & $74(31)$ & 94 & 65 \\
\hline $\begin{array}{l}\text { 6-Item Cognitive } \\
\text { Impairment } \\
\text { Test (O'Regan } \\
\text { et al, }{ }^{50} \text { 2017) }\end{array}$ & Medicine ward & 470 & 79 (17) & 81 & 31 \\
\hline $\begin{array}{l}\text { 3-Item Screener } \\
\text { (Steensma } \\
\text { et al, }{ }^{51} \text { 2019) }\end{array}$ & $\begin{array}{l}\text { General medicine } \\
\text { or surgery ward }\end{array}$ & 391 & $391(100)$ & 94 & 42 \\
\hline
\end{tabular}

Abbreviation: EEG, electroencephalography.

imperative to ensure that older adults can hear. Securing hearing aids is often practically challenging because older adults rarely plan to get critically ill and thus do not bring their hearing aids to the hospital, and families may not be available to retrieve them. Hearing aids are also notorious for disappearing during hospitalizations. In 
the absence of hearing aids, sound amplifiers (so-called pocket talkers) can be used to amplify sound, although they do not work for all types of hearing impairment.

Surgical masks worsen comprehension for older adults with hearing impairment. Transparent surgical masks have been developed and can facilitate enhanced comprehension for those with hearing impairment. ${ }^{52}$ Although not yet US Food and Drug Administration approved, they are in use for areas with personal protective equipment (PPE) shortages caused by COVID-19. ${ }^{53}$ It is also important to ensure that glasses are on to facilitate communication.

Even for individuals with hearing or vision impairment that cannot be remedied, the CAM-ICU can still be used reliably. For deaf individuals, the CAM-ICU can be administered with 2 exceptions: using the visual attention form for feature 2 , and written out questions and instructions for feature 4. For individuals who are blind, the CAM-ICU can be administered with 1 exception: the 2-stage command in feature 4 is not administered and any error on the 4 questions results in a positive feature 4 . For individuals who are both blind and deaf, cognitive assessment is much more challenging and often relies on observing level of consciousness to inform ratings of features 1 and 3 and using family observations whenever possible.

\section{Primary Neurologic Injury}

Stroke is an emerging complication of COVID-19. ${ }^{15}$ Delirium in neurocritically ill patients has been associated with prolonged hospital stay, ${ }^{54-56}$ worse functional status, ${ }^{56}$ and worse cognitive status. ${ }^{55,57}$ Because of the neurologic nature of the primary injury, it can be difficult to determine whether a change in mental status is caused by a new condition causing delirium or a continuation of the primary neurologic insult. Changes in mental status in this population may be driven by the deterioration caused by the primary neurologic disorder (eg, brain edema, vasospasm, seizures, rebleeding, and/or ischemia in patients with acute stroke). These patients are also prone to neck-down complications that may result in delirium.

Patel and colleagues ${ }^{58}$ performed a systematic review to identify valid and reliable tools to assess for delirium in primary neurocritically ill patients. Both the CAM-ICU and the ICDSC had fair sensitivity (62\%-76\%) and specificity (74\%-98\%) in this population.

\section{POTENTIAL DOWNSIDES TO SCREENING}

It is worth discussing the potential unintended consequences of delirium screening. As with any screening tool, false-negatives and false-positives arise. Relying too strongly on a binary result from a delirium screening tool can lead to discounting changes in mental status that do not meet criteria for delirium but still may signal an acute problem. A screen may miss a true case of delirium and more often may miss subsyndromal delirium (acute brain dysfunction that does not meet the full criteria for delirium). Missing subsyndromal delirium is particularly problematic because of its association with prolonged hospitalization, ${ }^{10,59}$ cognitive and functional decline, ${ }^{59}$ and institutionalization. ${ }^{59,60}$

In contrast, for false-positive cases, it may lead to unnecessary testing, prolonged hospitalization, and subsequently increased health care costs.

Another potential concern is that more identification of delirium may result in unnecessary pharmacologic treatment. One study in a surgical and trauma ICU found that communicating CAM-ICU screens to providers resulted in more days receiving antipsychotic medications compared with a group where the CAM-ICU was not communicated to providers, although total dose was no different. ${ }^{61}$ However, since this study, 
a robust evidence base has shown that antipsychotic medications do not shorten time in delirium, reduce mortality, length of stay, or other clinical outcomes. ${ }^{62}$ It is less likely that positive delirium screens would lead to increased prescribing of antipsychotics given the current evidence.

Despite these concerns, multiple professional societies and organizations continue to recommend delirium screening at least twice daily, especially given the large evidence base from the A2F bundle in improvements in clinical outcomes associated with the bundle's implementation. Especially in this pandemic, where the health care system is like a delirium factory, regular screening for delirium is imperative.

\section{SUMMARY}

The COVID-19 pandemic has raised many challenges in managing critically ill older adults with attention to delirium prevention and management. To spare this vulnerable population of older adults from poor outcomes associated with delirium, early recognition of delirium is critical. Despite the health care system limitations during this pandemic and the difficult clinical challenges, delirium screening and management remains an evidence-based cornerstone of critical care.

\section{CLINICS CARE POINTS}

- Older adults are particularly vulnerable during the COVID-19 pandemic, because higher age increases risk for both delirium and COVID-19-related death.

- The PADIS guidelines recommend delirium screening using the $\mathrm{CAM}-\mathrm{ICU}^{27}$ or the ICDSC. ${ }^{28}$

- Ensure communication during delirium screening is effective despite environmental barriers related to the pandemic (PPE, lack of family presence at the bedside), and restore sensory impairment as able (use hearing aids or sound amplifiers, reduce background noise, provide glasses).

- Always ask about a patient's baseline cognitive status. Never assume someone is demented because of age alone.

- Special considerations are necessary for patients with certain conditions (eg, sensory impairment, chronic neurodegenerative conditions, acute neurologic injury) that both increase risk for delirium and may be mistaken for delirium.

\section{DISCLOSURE}

E.W. Ely is currently receiving grant funding from NIA (\#R01AG058639) and NIGMS (\#R01GM120484) and serves as a consultant for Pfizer and Eli Lilly. The funding sources had no role in the preparation, review, or approval of the article, or in the decision to submit it for publication.

\section{REFERENCES}

1. Inouye SK, Westendorp RG, Saczynski JS. Delirium in elderly people. Lancet 2014;383(9920):911-22.

2. Hein C, Forgues A, Piau A, et al. Impact of polypharmacy on occurrence of delirium in elderly emergency patients. J Am Med Dir Assoc 2014;15(11): 850.e1-5.

3. Richardson S, Hirsch JS, Narasimhan M, et al. Presenting characteristics, comorbidities, and outcomes among 5700 patients hospitalized with COVID-19 in the New York City Area. JAMA 2020;323(20):2052-9. 
4. Ely EW, Shintani A, Truman B, et al. Delirium as a predictor of mortality in mechanically ventilated patients in the intensive care unit. JAMA 2004;291(14):1753-62.

5. Salluh JI, Wang H, Schneider EB, et al. Outcome of delirium in critically ill patients: systematic review and meta-analysis. BMJ 2015;350:h2538.

6. Pandharipande PP, Girard TD, Jackson JC, et al. Long-term cognitive impairment after critical illness. N Engl J Med 2013;369(14):1306-16.

7. Girard TD, Jackson JC, Pandharipande PP, et al. Delirium as a predictor of longterm cognitive impairment in survivors of critical illness. Crit Care Med 2010; 38(7):1513-20.

8. Mehta S, Cook D, Devlin JW, et al. Prevalence, risk factors, and outcomes of delirium in mechanically ventilated adults. Crit Care Med 2015;43(3):557-66.

9. Pisani MA, Kong SY, Kasl SV, et al. Days of delirium are associated with 1-year mortality in an older intensive care unit population. Am J Respir Crit Care Med 2009; 180(11): 1092-7.

10. Ouimet S, Riker R, Bergeron N, et al. Subsyndromal delirium in the ICU: evidence for a disease spectrum. Intensive Care Med 2007;33(6):1007-13.

11. Ely EW, Gautam S, Margolin R, et al. The impact of delirium in the intensive care unit on hospital length of stay. Intensive Care Med 2001;27(12):1892-900.

12. Witlox J, Eurelings LS, de Jonghe JF, et al. Delirium in elderly patients and the risk of postdischarge mortality, institutionalization, and dementia: a meta-analysis. JAMA 2010;304(4):443-51.

13. Maust D, Langa K, Solway E, et al. Thinking about brain health. University of Michigan National Poll on Healthy Aging.; 2019.

14. Spronk PE, Riekerk B, Hofhuis J, et al. Occurrence of delirium is severely underestimated in the ICU during daily care. Intensive Care Med 2009;35(7):1276-80.

15. Helms J, Kremer S, Merdji H, et al. Neurologic features in severe SARS-CoV-2 infection. N Engl J Med 2020;382(23):2268-70.

16. Hshieh TT, Yue J, Oh E, et al. Effectiveness of multicomponent nonpharmacological delirium interventions: a meta-analysis. JAMA Intern Med 2015;175(4): 512-20.

17. Barr J, Fraser GL, Puntillo K, et al. Clinical practice guidelines for the management of pain, agitation, and delirium in adult patients in the intensive care unit. Crit Care Med 2013;41(1):263-306.

18. Devlin JW, Skrobik Y, Gelinas C, et al. Clinical practice guidelines for the prevention and management of pain, agitation/sedation, delirium, immobility, and sleep disruption in adult patients in the ICU. Crit Care Med 2018;46(9):e825-73.

19. Berian JR, Rosenthal RA, Baker TL, et al. Hospital standards to promote optimal surgical care of the older adult: a report from the coalition for quality in geriatric surgery. Ann Surg 2018;267(2):280-90.

20. Balas M, Olsen K, Gannon D, et al. Safety and efficacy of the abcde bundle in critically-ill patients receiving mechanical ventilation. Crit Care Med 2012; 40(12):U18.

21. Marra A, Ely EW, Pandharipande PP, et al. The ABCDEF bundle in critical care. Crit Care Clin 2017;33(2):225-43.

22. Barnes-Daly MA, Phillips G, Ely EW. Improving hospital survival and reducing brain dysfunction at seven California community hospitals: implementing PAD guidelines via the ABCDEF bundle in 6,064 patients. Crit Care Med 2017;45(2): $171-8$.

23. Ely EW. The ABCDEF bundle: science and philosophy of how ICU liberation serves patients and families. Crit Care Med 2017;45(2):321-30. 
24. Pun BT, Balas MC, Barnes-Daly MA, et al. Caring for critically ill patients with the ABCDEF bundle: results of the icu liberation collaborative in over 15,000 adults. Crit Care Med 2019;47(1):3-14.

25. Hsieh SJ, Otusanya O, Gershengorn HB, et al. Staged implementation of awakening and breathing, coordination, delirium monitoring and management, and early mobilization bundle improves patient outcomes and reduces hospital costs. Crit Care Med 2019;47(7):885-93.

26. Critical illness BdaSC. Delirium in the intensive care Unit: a Guide for families and patients. Available at: https://uploads-ssl.webflow.com/5b0849daec50243 a0a1e5e0c/5e7b9a2fb906fb34322404ee_CIBS-Center-Delirium-Brochure.pdf. Accessed April 16, 2020.

27. Ely EW, Truman B, May L, et al. Validation of the CAM-ICU for delirium assessment in mechanically ventilated patients. J Am Geriatr Soc 2001;49(4):S2.

28. Bergeron N, Dubois MJ, Dumont M, et al. Intensive care delirium screening checklist: evaluation of a new screening tool. Intensive Care Med 2001;27(5): 859-64.

29. Gelinas C, Berube M, Chevrier A, et al. Delirium assessment tools for use in critically ill adults: a psychometric analysis and systematic review. Crit Care Nurse 2018;38(1):38-49.

30. Gusmao-Flores D, Salluh JI, Chalhub RA, et al. The confusion assessment method for the intensive care unit (CAM-ICU) and intensive care delirium screening checklist (ICDSC) for the diagnosis of delirium: a systematic review and meta-analysis of clinical studies. Crit Care 2012;16(4):R115.

31. Inouye SK, van Dyck CH, Alessi CA, et al. Clarifying confusion: the confusion assessment method. A new method for detection of delirium. Ann Intern Med 1990;113(12):941-8.

32. Sessler CN, Gosnell MS, Grap MJ, et al. The Richmond Agitation-Sedation Scale: validity and reliability in adult intensive care unit patients. Am J Respir Crit Care Med 2002;166(10):1338-44.

33. Ely EW, Truman B, Shintani A, et al. Monitoring sedation status over time in ICU patients: reliability and validity of the Richmond Agitation-Sedation Scale (RASS). JAMA 2003;289(22):2983-91.

34. Riker RR, Picard JT, Fraser GL. Prospective evaluation of the Sedation-Agitation Scale for adult critically ill patients. Crit Care Med 1999;27(7):1325-9.

35. Ely EW, Inouye SK, Bernard GR, et al. Delirium in mechanically ventilated patients: validity and reliability of the confusion assessment method for the intensive care unit (CAM-ICU). JAMA 2001;286(21):2703-10.

36. Institute for Healthcare Improvement. Age-friendly health systems Guide to using 4Ms CAre. Available at: http://www.ihi.org/Engage//nitiatives/Age-FriendlyHealth-Systems/Documents/IHIAgeFriendlyHealthSystems_GuidetoUsing4Ms Care.pdf. Accessed February 10, 2020.

37. Han JH, Wilson A, Vasilevskis EE, et al. Diagnosing delirium in older emergency department patients: validity and reliability of the delirium triage screen and the brief confusion assessment method. Ann Emerg Med 2013;62(5):457-65.

38. Physicians ACoE. Geriatric emergency departments guidelines. Available at: https:// www.acep.org/globalassets/new-pdfs/policy-statements/geriatric-emergencydepartment-guidelines.pdf. Accessed April 16, 2020.

39. Morandi A, Davis D, Fick DM, et al. Delirium superimposed on dementia strongly predicts worse outcomes in older rehabilitation inpatients. J Am Med Dir Assoc 2014; 15(5):349-54. 
40. Fong TG, Jones RN, Shi $P$, et al. Delirium accelerates cognitive decline in Alzheimer disease. Neurology 2009;72(18):1570-5.

41. Livingston G, Sommerlad A, Orgeta V, et al. Dementia prevention, intervention, and care. Lancet 2017;390(10113):2673-734.

42. Jackson TA, MacLullich AM, Gladman JR, et al. Diagnostic test accuracy of informant-based tools to diagnose dementia in older hospital patients with delirium: a prospective cohort study. Age Ageing 2016;45(4):505-11.

43. Duggan MC, Morrell ME, Chandrasekhar R, et al. A brief informant screening instrument for dementia in the ICU: the diagnostic accuracy of the AD8 in critically ill adults suspected of having pre-existing dementia. Dement Geriatr Cogn Disord 2020;48(5-6):241-9.

44. Lyketsos CG, Lopez O, Jones B, et al. Prevalence of neuropsychiatric symptoms in dementia and mild cognitive impairment: results from the cardiovascular health study. JAMA 2002;288(12):1475-83.

45. Jost BC, Grossberg GT. The evolution of psychiatric symptoms in Alzheimer's disease: a natural history study. J Am Geriatr Soc 1996;44(9):1078-81.

46. Ballard C, Aarsland D, Francis P, et al. Neuropsychiatric symptoms in patients with dementias associated with cortical Lewy bodies: pathophysiology, clinical features, and pharmacological management. Drugs Aging 2013;30(8):603-11.

47. Brown LJ, Fordyce C, Zaghdani $H$, et al. Detecting deficits of sustained visual attention in delirium. J Neurol Neurosurg Psychiatry 2011;82(12):1334-40.

48. Morandi A, McCurley J, Vasilevskis EE, et al. Tools to detect delirium superimposed on dementia: a systematic review. J Am Geriatr Soc 2012;60(11):2005-13.

49. Bellelli G, Morandi A, Davis DH, et al. Validation of the 4AT, a new instrument for rapid delirium screening: a study in 234 hospitalised older people. Age Ageing 2014;43(4):496-502.

50. O'Regan NA, Maughan K, Liddy N, et al. Five short screening tests in the detection of prevalent delirium: diagnostic accuracy and performance in different neurocognitive subgroups. Int J Geriatr Psychiatry 2017;32(12):1440-9.

51. Steensma E, Zhou W, Ngo L, et al. Ultra-brief screeners for detecting delirium superimposed on dementia. J Am Med Dir Assoc 2019;20(11):1391-6.e1.

52. Atcherson SR, Mendel LL, Baltimore WJ, et al. The effect of conventional and transparent surgical masks on speech understanding in individuals with and without hearing loss. J Am Acad Audiol 2017;28(1):58-67.

53. Available at: http://www.theclearmask.com. Accessed April 22, 2020.

54. Mitasova A, Kostalova M, Bednarik J, et al. Poststroke delirium incidence and outcomes: validation of the confusion assessment method for the intensive care Unit (CAM-ICU). Crit Care Med 2012;40(2):484-90.

55. Naidech AM, Beaumont JL, Rosenberg NF, et al. Intracerebral hemorrhage and delirium symptoms. Length of stay, function, and quality of life in a 114-patient cohort. Am J Respir Crit Care Med 2013;188(11):1331-7.

56. Oldenbeuving AW, de Kort PL, Jansen BP, et al. Delirium in the acute phase after stroke: incidence, risk factors, and outcome. Neurology 2011;76(11):993-9.

57. Rosenthal LJ, Francis BA, Beaumont JL, et al. Agitation, delirium, and cognitive outcomes in intracerebral hemorrhage. Psychosomatics 2017;58(1):19-27.

58. Patel MB, Bednarik J, Lee P, et al. Delirium monitoring in neurocritically ill patients: a systematic review. Crit Care Med 2018;46(11):1832-41.

59. Cole M, McCusker J, Dendukuri N, et al. The prognostic significance of subsyndromal delirium in elderly medical inpatients. J Am Geriatr Soc 2003;51(6): 754-60. 
60. Brummel NE, Boehm LM, Girard TD, et al. Subsyndromal delirium and institutionalization among patients with critical illness. Am J Crit Care 2017;26(6):447-55.

61. Bigatello LM, Amirfarzan H, Haghighi AK, et al. Effects of routine monitoring of delirium in a surgical/trauma intensive care unit. J Trauma Acute Care Surg 2013;74(3):876-83.

62. Girard TD, Exline MC, Carson SS, et al. Haloperidol and Ziprasidone for treatment of delirium in critical illness. N Engl J Med 2018;379(26):2506-16.

63. Erkinjuntti T, Sulkava R, Wikstrom J, et al. Short portable mental status questionnaire as a screening-test for dementia and delirium among the elderly. J Am Geriatr Soc 1987;35(5):412-6.

64. Hestermann U, Backenstrass M, Gekle I, et al. Validation of a German version of the Confusion Assessment Method for delirium detection in a sample of acute geriatric patients with a high prevalence of dementia. Psychopathology 2009; 42(4):270-6.

65. Rosen J, Sweet RA, Mulsant BH, et al. The Delirium Rating Scale in a psychogeriatric inpatient setting. J Neuropsychiatry Clin Neurosci 1994;6(1):30-5.

66. Hart RP, Levenson JL, Sessler CN, et al. Validation of a cognitive test for delirium in medical ICU patients. Psychosomatics 1996;37(6):533-46.

67. Ely EW, Margolin R, Francis J, et al. Evaluation of delirium in critically ill patients: validation of the confusion assessment method for the intensive care Unit (CAMICU). Crit Care Med 2001;29(7):1370-9.

68. Thomas C, Hestermann U, Walther S, et al. Prolonged activation EEG differentiates dementia with and without delirium in frail elderly patients. J Neurol Neurosurg Psychiatry 2008;79(2):119-25. 